\title{
Polymeric Coatings Composition Based on Modified Oligopiperylene Styrene Binders with Galvanic Sludge as a Filler
}

\author{
T.A. Trifonova, O.G. Selivanov", N.V. Chukhlanova, N.V. Selivanova \\ Department of Ecology, Vladimir State University, Vladimir, Russia \\ *Corresponding author: Selivanov6003@mail.ru
}

Received June 18, 2013; Revised October 30, 2013; Accepted November 11, 2013

\begin{abstract}
The possibility of development of new coating materials based on oligopiperylene styrene modified with alkoxysilane and galvanic sludge as a pigment-filler is presented in this article. The nanostructure of the coating surface and the influence of the composition and nature of the components of paint and varnish materials on its property are studied. These materials are intended for protection buildings from the effects of adverse factors.
\end{abstract}

Keywords: polymeric coatings, oligopiperylen styrene, galvanic sludge, galvanic slurry

Cite This Article: T.A. Trifonova, O.G. Selivanov, N.V. Chukhlanova, and N.V. Selivanova, "Polymeric Coatings Composition Based on Modified Oligopiperylene Styrene Binders with Galvanic Sludge as a Filler." Chemical Engineering and Science 1, no. 4 (2013): 75-78. doi: 10.12691/ces-1-4-5.

\section{Introduction}

Nowadays polymer paint and varnish materials have been really widely applied in construction. Especial interest is caused by the application of polymer paint and varnish materials as protection coating for building and structures elements against negative effect of natural and anthropogenic factors. Such factors include construction materials ablation caused by frozen capillary moisture at low temperatures, acid rain impact, UV radiation, atmospheric ozone, flame etc.

However when developing protective coatings it should be primarily considered that most polymer materials produces on a large industrial scale are not sufficiently stable to the mentioned above negative factors. In this connection the usage of organic polymers, modified with organic-silicon compounds with block-copolymer or interpenetrating grids [1,2], presents special interest. These materials are highly stable not only to elevated temperatures and UV-radiation, but also to atmospheric moisture impact. It is explained by the fact that such modification causes the strongest hydrophobic effect.

In previously published reports [3,4,5] filler-free protection varnish compositions with water-repellent effect based on oligopiperylene styrene modified with alcoxysilane have been studied [6]. Such compounds were jointly developed by the Vladimir State University and "VladDorNII ltd". Industrial operation of these compounds since 2003 as a part of combined protection coating, where varnish was used as undercoat for enamel KO-168, revealed rather highly effectiveness of the suggested materials.

The research objective was the development of enamel possessing high hydrophobic properties based on oligopiperylene styrene binding modified with tetraethoxysilane and filling based on galvanic slurry for protecting ferroconcrete buildings and structures. The choice of galvanic slurry, used as a filling, is explained by the relevant search of such solutions, which solve ecologic problems alongside with the improvement of technical properties of polymer paint and varnish. Nowadays galvanic slurry is utilized at industrial landfills and many valuable components contained in the slurry such as zinc, copper, nickel, chromium etc. are lost. Besides environment is polluted $[7,8]$ as heavy metals compounds can be leached from landfill and get into underground waters, water bodies with leachate and get involved in biospheric cycles (especially if a landfill does not correspond the requirements of Sanitary Standard SNiP 2.01.28-85) That is why the most rational direction of galvanic slurry utilization is to use it as filling pigment for paint and varnish production.

\section{Objects and Methods}

Oligopiperylene styrene [OPPS] - oligomer PS-70M was used as binding material, which is concentrated OPPS solution in organic solvent and tetraethoxysilane [TEOS] was used as a modification agent.

Galvanic slurry - residual from effluents neutralization [9,10,11,12] - was applied as a filling material. Galvanic slurry is a paste consisting mainly of metal hydroxide. Galvanic slurry from landfill "Novoalexandrovo" in Vladimir region. was used as a filling pigment. Galvanic slurry was submitted to thorough drying at $250^{\circ} \mathrm{C}$ and further to grinding by ball mill. The product had the following characteristics: grit rate - max 30 micron, water-soluble substances mass concentration $-0,23$, oil 
absorption - 32g/100g, spreading capacity $-55 \mathrm{~g} / \mathrm{m}^{2}$. To determine element content of filling-pigment X-ray spectrometer "Spectroscan MAX" was applied. This spectrometer receives spectrum of roentgen fluorescent radiation from the analyzed sample as a result of exposure by acute focal X-ray tube. Spectrum bands intensiveness corresponds to the content of the determined elements of the sample. The content is presented in Table 1.

Table 1. Galvanic slurry content

\begin{tabular}{|c|c|}
\hline Element (as oxide or hydroxide) & Amount, \% \\
\hline $\mathrm{Sr}$ & 0,060 \\
$\mathrm{Zn}$ & 10,90 \\
$\mathrm{Cu}$ & 1,600 \\
$\mathrm{Ni}$ & 1,200 \\
$\mathrm{Co}$ & 0,004 \\
$\mathrm{Fe}$ & 6,640 \\
$\mathrm{Mn}$ & 0,200 \\
$\mathrm{Cr}$ & 4,700 \\
$\mathrm{~V}$ & 0,002 \\
$\mathrm{Ti}$ & 0,005 \\
$\mathrm{Si}, \mathrm{O}$ & others \\
\hline
\end{tabular}

Background radiation, measured with device «AQM22» showed the absence of radioactive radiation in the product.

Research methods: the method of measuring dampening contact angle implied dripping on a base, its microphotography with further contact angle measuring with protractor, viscosity on funnel FORD №4 (ASTM D 120087), adhesion on concrete applying adhesionmeter PSO - MG4 for ASTM D 4541. Relative hardness was determined by comparing the number of oscillations of a pendulum and ball joints on glass and polymer film by pendulum ASTM D4366-95 (ISO1522:2001). Surface structure was researched with atomic-force microscopy (AFM) at a scanning probing system Integra Aura, manufactured at NT-MDT, Zelenograd. The scanning was carried out by polysilicon sounder HA_NC applying discrete contact method. According to this method cantilever pressure on sample surface is considerably less, this allows to operate with softer and easily destructive materials like polymer films and biomaterials.

To determine integral toxicity rate of polymer paint and varnish material integral toxicity rate was apply biotest "Ecolum" at the "Biotox-10" device. Frozen-dried preparation of luminescent bacteria or enzymatic agents of bacterial luciferase.

Toxicity criterion was the determination of test-object bioluminescence intensity with the device "Biotox-10" under the impact of chemical compounds contained in the analyzed sample compared to solution free of toxic substances.

\section{Experiment Results and Discussion}

At the first stage of the research we have supposed that there possibly is the mechanism of interation between oligopiperylene styrene and alcoxysilane. The authors supposed that chemical bonds might be formed between these two substances due to the existence of reaction capable groups in TEOS and multiple bonds in OPPS.

The interaction product of oligopiperylene styrene and tetraethoxysilane most probably is a three-dimensional polymer, where macromolecules of OPPS are stitched by TEOS molecules. The basis of this reaction is hydrogen atoms replacement which are at allile position towards double bond of copolymer. The interaction of oligopiperylene styrene and tetraethoxysilane can proceed both from the point of view of modification by alcoxysilane polycondensation products and possible chemical interaction of these components.

The first and the second interaction variants assume the alteration of physical and physical-mechanical properties of polymer binding material.

One of the most noticeable changes during modification by alcoxysilanes is the occurrence of strong hydrophobic effect.

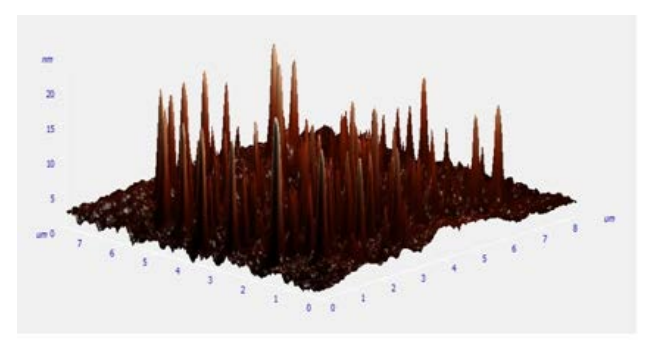

a

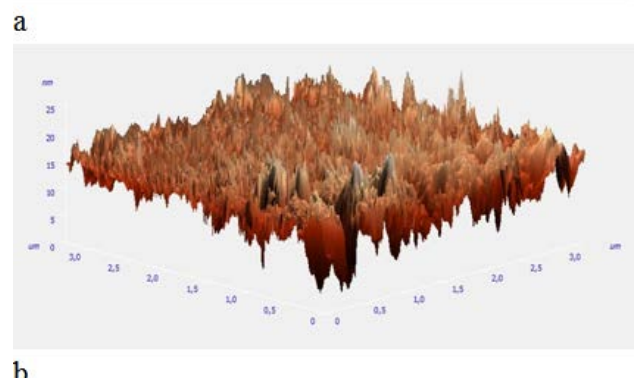

$\mathrm{b}$

Figure 1. Film surface structure of oligopiperylene styrene (a) and oligopiperylene styrene, modified with ten per cent of alcoxysilane (b) at the edge of galvanic slurry particle

The effect itself appears when alcoxysilane content in binding material is only $4 \%$. Hydrophobic effect is usually explained by the fact that TEOS possesses functional groups of silicon atom, which promote the formation of bonds with the surface of the treated material. TEOS molecules are oriented in such a way that, for instance, a polar hydrocarbon fragments are directed towards the outer space, but polar ones - towards the treated surface. As a result the latter in protected by hydrophobic hydrocarbon groups and loses its ability to be moisteneed by water. On the treated surface the finest layer of substance is formed, but not a complete coating, due to which vapour and gas permeability preserved. This property is of great importance for numerous construction materials [13].

The described above experimentally tested assumptions prove the tests executed applying atomic-force microscope.

Figure 1 demonstrates 3D film surface of oligopiperylene styrene (a), modified oligopiperylene styrene with $10 \%$ of alcoxysilane (b) at the galvanic slurry particle section (extruded filling had undergone prelapping with the following polishing). As the research showed unmodified oligopiperylene styrene contains not numerous spheric inclusions with the diameter of 700-800 nanometers. These are probably oligopiperylene globules. Such structure is basically typical for polystyrene modified with diene oligomers. However, when introducing alcoxysilane, 3D surface image is completely 
changing. Almost all surface consists of comparatively shallow but numerous (100 per 1 square micrometer) formations, located athwart the coating surface. Judging by the neoformations effective diameter of 2-5 nanometer they are polarized elongated fragments of three dimension macromolecules of polymer structure, formed during the interation of TEOS and oligopiperylene styrene [14].

The question arises concerning the role and impact of galvanic slurry when it is introduced into the composition. As galvanic slurry consists of metals oxides and hydroxides it will undoubtedly lead to the occurrence of numerous associated hydrogen bonds between filling and binding materials. The possibility of chemical interaction of hydroxyl groups on the surface of filling and binding materials cannot be eliminated. The distribution of galvanic slurry particles in the binding material is rather homogeneous. As zinc oxide is a prevailing component so considerable spreading capacity is provided. Coloristic characteristics of calm greenish-grey color are optimal for painting most of industrial and civil buildings and structures.

During the protection coating maintenance the most important characteristic is its hardness. Relative hardness was determined applying pendular device M-3 According to the research hardness is defined by both TEOS modifier content and galvanic slurry as a filling material. Research results are presented in Figure 2.

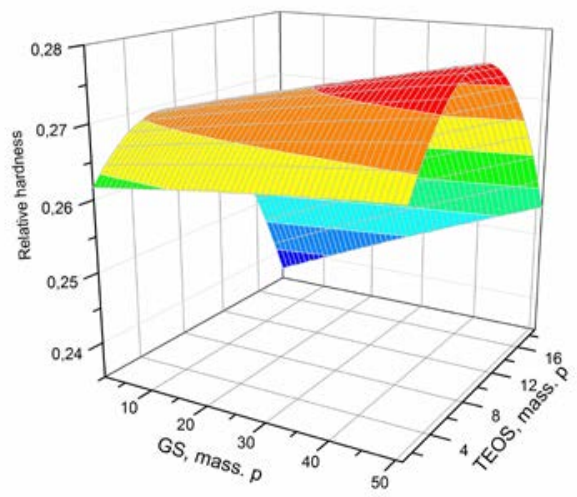

Figure 2. Dependence surface of enamel relative hardness properties on TEOS and GS content

OPPS-TEOS-GS composition hardness is connected with the formation of intermolecular stitches (in case of relative hardness decrease), and also with the plastification effect (in case of relative hardness decrease). The process of composition hardening has competing nature and depends on coating drying rate, on the number of the formed stitches and many other factors. Anyway great amount of alcoxysilane is unprofitable.

Nevertheless it should be noted that the highest relative hardness values are observed when galvanic slurry is added. Slurry taken from dumps contains quarts sand, which increases the hardness of the total composition.

Long-term maintenance of protective coating greatly depends on adhesion towards the coated construction material. Coating adhesion properties are determined by the complex interaction (physical, chemical, electric) of polymer functional groups and active centers of substrate material. The originated bonds impede the interaction of this material and environmental particles, i.e. corrosion process. That means, the higher is adhesion the more bonds of substrate and polymer appear, and the stronger are these bonds, the less vacant places for corrosion remain. Coating test results on the grinding concrete are presented in Figure 3.

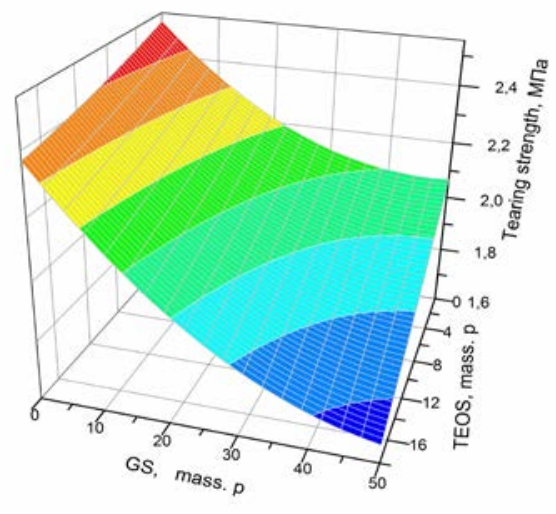

Figure 3. Dependence surface of enamel adhesion properties on TEOS and GS content

The research showed that solidity maximum limit for tearing off is achieved when tetraethoxysilane modifier content is $10 \%$. Its further concentration increase considerably decreases the characteristics that might be connected to plastification effect. However galvanic slurry content does not appreciably influence hardness limit for tearing off. Thus high adhesion of film forming polymer of oligopiperylene styrene is achieved due to id modification with tetraethoxysilane. As previously described such composition macromolecules are polarized and possess a great number of chemically active functional groups, which promote the formation of oriented adsorption layer tightly binding film and substrate by tetraethoxysilane $[15,16]$. Basing on the research adhesion rate in this case is determined by the force of possible physical and chemical interaction of TEOS and hydroxyl groups on the concrete substrate surface.

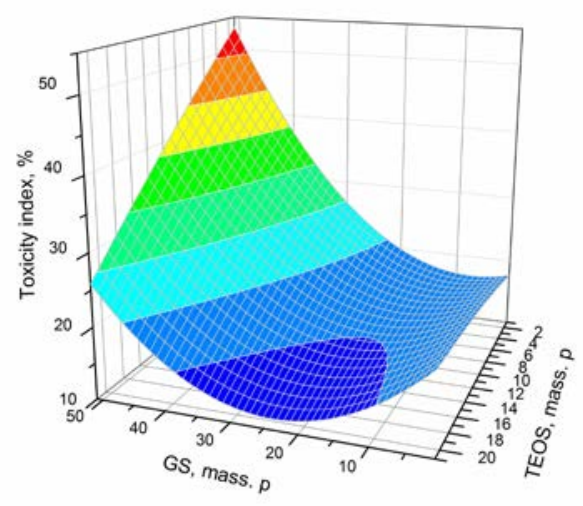

Figure 4. Dependence surface of toxicity index on TEOS and GS content

Toxicity estimation of the developed paint and varnish polymer coating was executed applying the device "Biotox-10" for ecological control. The research results demonstrated (Figure 4) that the addition of 30 mass.p of GS into the formulation does not influence coating toxicity rate, which is apparently specified by a number of favorable factors: GS addition prior to composition 
hardening, GS homogeneous distribution along the paint and varnish film, hardening and three-dimension grid structure formation as a result of TEOS modification occurs without any hindrance from GS, and at the same time promotes safe blocking of GS, containing heavy metals ions inside three-dimension stitched structure after polymerization process and does not allow the migration from polymer film into environment. The carried analysis of developed paint and varnish water extract showed that toxicity index does not exceed 20 units, so the paint and varnish material can be referred to the materials with the admissible toxicity rate (according to MU №1.018-07) and consequently to ecologically safe materials.

Comparative characteristics of enamel KO-168 and the developed enamel containing 100 mass.p of OPPS, 30 mass.p. of GS and 10 mass.p. of TEOS with $30-35 \%$ of aliphatic solvent of total mass are given in Table 2 .

Table 2. Comparative characteristics of popular enamel KO-168 and developed enamel containing 100 mass.p of OPPS 30 mass.p. of GS and 10 mass. p. TEOS with addition of aliphatic solvent $30-35 \%$ of total mass

\begin{tabular}{|c|c|c|c|}
\hline$\#$ & Characteristic & \multicolumn{2}{|c|}{ Value } \\
\hline \multicolumn{2}{|r|}{ Ready material } & КО-168 & Developed \\
\hline 1. & $\begin{array}{l}\text { Relative viscosity according to } \\
\text { viscosity meter VZ-4 at } \\
(20 \pm 0,5){ }^{\circ} \mathrm{C} \text {, }\end{array}$ & $20-45$ & $20-50$ \\
\hline 2. & $\begin{array}{l}\text { Mass share of non-volatile } \\
\text { substance, } \% \text {, min }\end{array}$ & 60 & 60 \\
\hline \multicolumn{2}{|r|}{ Dry paint and varnish film } & & \\
\hline 1. & Film appearance & Semi-flat & Semi-flat \\
\hline 2. & Film color & Grey & Grey \\
\hline 3. & $\begin{array}{l}\text { Exposition prior to second layer } \\
\text { coating, hour }\end{array}$ & 24 & 8 \\
\hline 4. & One-layer outlay, $\mathrm{g} / \mathrm{m}^{2}$ & $120-180$ & $120-150$ \\
\hline 5. & $\begin{array}{c}\text { One-layer dry coating thickness, } \\
\text { mcm }\end{array}$ & $18-25$ & $25-35$ \\
\hline 6. & Bending elasticity, mm, max & 3 & 3 \\
\hline 7. & $\begin{array}{c}\text { Enamel film hardness according to } \\
\text { pendular device TML (pendular } \\
\text { A), unit, min }\end{array}$ & 0,25 & 0,30 \\
\hline 8. & $\begin{array}{c}\text { Dry film coating, } \mathrm{g} / \mathrm{m}^{2} \text {, max, for } \\
\text { grey enamel }\end{array}$ & 80 & 60 \\
\hline 9. & Moisten contact angle, degr & 94 & 107 \\
\hline
\end{tabular}

To compare protection properties the concrete samples were coated with organic-silicon enamel KO-168 and the developed enamel applying pneumatic atomizer. In both cases oligopiperylene styrene varnish modified with $10 \%$ of TEOS was used as a substrate. After drying they were exposed to standard cyclic tests for frost-resistance according to State Standard GOST 10060.1-95 «Basic method of frost-resistance determining». Further tests of concrete samples strength characteristics for compression revealed that enamels have similar protection properties and averagely increase frost-resistance in $\min 80 \%$. However production price of organic-silicon enamel several times exceeds the price of the developed composition.

\section{Conclusions}

Integrated application of using tetraethoxysilane and galvanic slurry modifier in the composition based on oligopiperylene styrene allows to receive protection coating with the increased maintenance properties. The best characteristics are revealed when a modifier is added in the amount of $100 \%$ of oligopiperylene styrene mass. Thus the carried out research demonstrate real possibility of creating new ecologically safe paint and varnish materials based on modified oligopiperylene styrene binding filled with galvanic slurry for protecting buildings and structures against natural and anthropogenic negative factors Simultaneously ecological problems are solved, connected to galvanic industry waste - galvanic slurryutilization.

\section{Acknowledgement}

Participants of the research are thankful to RF Education Ministry for the financial support in research” (Contract №160/B/4276/12 dated 15.10.2012).

\section{References}

[1] Sobolevsky M.V. and others. Organic-silicon products properties and application. / M.V. Sobolevsky.-M.: Chemistry, 1975, 296.

[2] V.Y. Chukhlanov and M.Ionova. Modification of One-component Polyurethane by Organosilicone // American Journal of Polymer Science, Vol.2(5), 2012,.129-134.

[3] Kriushenko S.S., Chukhlanov V.Y. Heat insulated polyurethane foam modified with polymethylphenylisiloxanes, SWorld -2-12 October 2012 -2-12 October 2012, 149.

[4] Chukhlanov V.Y., Nikonova N.Y., Alexeenko A.N. Hydrophobic liquid for concrete and metal-concrete structures. - $\mathrm{M}$ : Construction materials., 2003. № 12, 28-29.

[5] Chucklanov V.Y., Kolysheva N.A. New polymer binders based on oligopiperylene styrene and alkoxysilanes // Polymer Science and Technology. England, 2008. - Vol. 35 №6.,58.

[6] S.D. Popova etc. Film-formation properties of piperylene styrene copolymer SKPS-70M. - M: Paint and varnish materials and their application, 1986, №2,.39.

[7] Trifonova T.A., Mishchenko N.V., Budacov D.A. The Use of an Information Analitic system in soil-ecological studies // Eurasian Science, Vol.40(1),2002, 18-25.

[8] Sistem in Soil-Ecological Studies // Eurasian Soil Science.-2007.Vol.40, No 1,18-25.

[9] Shirkin L.A., Trifonova T.A., Selivanova N. , Gruzdkov D. The heavy metals migration from industrial wastes in soils // The 4th International Conference on Soils of Urban, Industrial, Traffic, Mining and Military Areas (SUITMA)-25, October, 2007, Nanjing, China. Programme, Abstracts \& Participant list. 178.

[10] Industrial Wastes in Soils. //Abstracts Eurosoil, Freiburg, Germany, September, 2004, 286-289.

[11] Trifonova T.A., Selivanova N.V. Ilyina M.E., Shirkin L.A. Galvanic slurry utilization. - Vladimir, BOOО ВОИ « Rost», 2011, 140.

[12] Patent. 2396051 France., МКІ C09C 1/24, 3/06; С09Д 5/08. Pigment anticorrosio et peinture aquense anticorrosive/ Hajime Makino, Wataru Minoda. Application 22.06.78; Publ. 26.01.79.

[13] Patent 2055086 RF, C04 B 33/14. Pigment and method of production / Kuznetsov V.S.; Zamishlaev V.G. Application 19.04.1993; Publ. 27.02.1996.

[14] Polymer encyclopedia. - M: Soviet encyclopedia., 1986.,625.

[15] Bazhant V etc. Silicones. Organic-silicon compounds, production, properties and application / Bazhant V, Khvalovsky V., Ratousky I.-M.: State science publish., 1960, 710.

[16] Tsipkina O.Y. Hydroinsulating and corrosion resistance protection of concrete buildings and structures. - Kiev: Будівельник, 1977, 80. 